\title{
The Long Search for Pharmacologically Useful Anti-Inflammatory Flavonoids and Their Action Mechanisms: Past, Present, and Future
}

\author{
Hyun Pyo Kim* \\ College of Pharmacy, Kangwon National University, Chunchon 24341, Republic of Korea
}

\begin{abstract}
Flavonoids are known to exert anti-inflammatory effects. Their pharmacological activities have been proved using various in vitro and in vivo models. Although their action spectrum and potencies are not adequate to alleviate acute inflammatory disorders, they have the potential to treat chronic inflammatory diseases. Recent investigations have revealed that inflammatory processes are involved in many disease processes and conditions. Some examples are skin disorders, cartilage diseases, metabolic inflammatory diseases, and aging. The effects of flavonoids on these disorders have been examined. Several possible application areas for flavonoids have been studied. Local treatment of these disorders with flavonoids is favorable to avoid systemic transformation. In this review, the findings based on the experimental results from my laboratory are summarized and the future possibility of using flavonoids clinically is discussed.
\end{abstract}

Key Words: Flavonoid, Anti-inflammation, Drug candidate, Chronic inflammation

\section{ANTI-INFLAMMATORY ACTION OF FLAVONOIDS}

Different types of flavonoids (Fig. 1) from plant origins have been known to possess anti-inflammatory activity in vitro as well as in vivo for decades (For reviews: Kim et al., 1996, 2000). Among these, certain derivatives were reported to possess strong potency at pharmacologically relevant doses. However, some of the reports do not have strong support from researchers including natural product research scientists. To analyze the real in vivo potency of flavonoids, more than 50 flavonoid derivatives were isolated from plant extracts and the in vivo activity of these and some commercially available derivatives was elucidated by oral administration to animal models of acute inflammation in my laboratory. The results were largely disappointing (Kim et al., 1993; Lee et al., 1993, 1994). Regardless of the structural varieties, which included aglycones, glycosides, flavones, flavonols, isoflavones, and flavanes, most of them did not show strong and meaningful action. Although some flavonoids like kaempferol and quercetin showed anti-inflammatory activity, their potencies were relatively weak when administered orally. Even the most active one (quercetin) only showed approximately $1 / 32$ potency of the $E D_{50}$ value of the reference drug hydrocortisone in the croton oil-induced ear edema test in mice. Apigenin, quercetin, and biochanin A showed only 1/52, 1/48, and 1/67 potencies, respectively, compared to the reference drug indomethacin in arachidonic acid-induced ear edema in mice. Therefore, it is clear that most flavonoids may not be suitable as antiinflammatory agents for acute inflammatory disorders, specifically by oral treatment. In contrast, the same studies revealed that local treatment with flavonoids showed some potential. For instance, the topical treatment of mouse skin with certain flavonoids (flavone and apigenin) exerted considerable and meaningful activity (1/6 and $1 / 14$ potencies) compared to indomethacin in the arachidonic acid-induced ear edema test.

In the early 1990s, the isoforms of cyclooxygenases (COX) and nitric oxide synthase (NOS) were newly discovered, and these enzymes were found to be closely related to inflammatory disorders. Several previous investigations demonstrated that certain flavonoids had the capacity to inhibit the enzymatic activity of the constitutive form of cyclooxygenase, COX-1 (For review: Kim et al., 2000). However, most flavonoids do not possess COX-1 inhibitory ability. In my laboratory, quercetin was found to weakly inhibit COX-1 from guinea pig epidermal tissue (Kim et al., 1998b). The other examples are the flavone derivatives (apigenin and oroxylin A) isolated

\section{Open Access https://doi.org/10.4062/biomolther.2022.004}

This is an Open Access article distributed under the terms of the Creative Commons Attribution Non-Commercial License (http://creativecommons.org/licenses/by-nc/4.0/) which permits unrestricted non-commercial use, distribution, and reproduction in any medium, provided the original work is properly cited.
Received Jan 6, 2022 Accepted Jan 13, 2022

Published Online Feb 7, 2022

\section{${ }^{*}$ Corresponding Author}

E-mail: hpkim@kangwon.ac.kr

Tel: +82-33-250-6910, Fax: +82-33-255-7865 
<smiles>O=C1CC(c2ccccc2)Oc2ccccc21</smiles><smiles>O=c1cc(-c2ccccc2)oc2ccccc12</smiles><smiles>O=c1c(O)c(-c2ccccc2)oc2ccccc12</smiles><smiles>O=c1cc(-c2ccccc2)oc2ccccc12</smiles>

Flavan<smiles>O=c1c(-c2ccccc2)coc2ccccc12</smiles>
Isoflavone<smiles>O=C(/C=C/c1ccccc1)c1ccccc1</smiles>

Chalcone<smiles>O=c1cc(-c2ccc(O)cc2)oc2cc(O)cc(O)c12</smiles><smiles>COc1c(O)cc(O)c2c(=O)cc(-c3ccccc3)oc12</smiles><smiles>O=c1cc(-c2ccc(O)c(O)c2)oc2cc(O)cc(O)c12</smiles><smiles>O=c1c(O)c(-c2ccc(O)cc2)oc2cc(O)cc(O)c12</smiles><smiles>O=c1c(O)c(-c2ccc(O)c(O)c2)oc2cc(O)cc(O)c12</smiles><smiles>CC(C)=CCc1c(-c2ccc(O)cc2O)oc2c3c(cc(O)c2c1=O)OC(C)(C)C=C3</smiles><smiles>C=C(C)C(CC=C(C)C)Cc1c(O)cc(O)c2c1O[C@H](c1ccc(Cl)cc1O)CC2=O</smiles><smiles></smiles><smiles>COc1cc(O)c2c(=O)cc(-c3ccc(OC)c(-c4c(O)cc(O)c5c(=O)cc(-c6ccc(O)cc6)oc45)c3)oc2c1</smiles>

Fig. 1. Basic chemical structures of plant flavonoids and some pharmacologically-active structures.

from the radix of Scutellaria baicalensis and isoflavone (tectorigenin) isolated from the rhizome of Belamcandae chinensis. They weakly inhibited COX-1 at $100 \mu \mathrm{M}$ (You et al., 1999). As shown by these previous studies, some flavonoids inhibited COX-1 enzymatic activity, but their potencies were relatively weak. There are several exceptions. These are the prenylated flavanones including kurarinone and sophoraflavanone $\mathrm{G}$ (Chi et al., 2001b) and the biflavonoid, amentoflavone (Kim et al., $1998 \mathrm{~b})$. The $\mathrm{IC}_{50}$ values of kurarinone and sophoraflavanone $\mathrm{G}$ were $0.1-1.0 \mu \mathrm{M}$ against COX-1 from bovine platelets $\left(\mathrm{IC}_{50}\right.$ of indomethacin, 0.4-1.3 $\mu \mathrm{M})$ and $\mathrm{IC}_{50}$ value of amentoflavone was $1 \mu \mathrm{M}$ against COX-1 from guinea pig epidermis $\left(\mathrm{IC}_{50}\right.$ of indomethacin, $3 \mu \mathrm{M}$ ). Nonetheless, it was concluded that most flavonoids do not significantly affect COX-1 activity while some flavonoids only weakly inhibit COX-1 activity.

As a part of a cellular mechanism study, my laboratory also tried to find the effect of flavonoids on the inducible form of cyclooxygenase, COX-2, since the effect on COX-2 was obscure. Most flavonoids did not affect COX-2 activity even at high concentrations $(>100 \mu \mathrm{M})$. Only several derivatives such as quercetin and several prenylated flavonoids including morusin and saggenone $D$ possessed $I_{50}$ values of approximately $100 \mu \mathrm{M}\left(\mathrm{IC}_{50}\right.$ of indomethacin, 1.5-5.0 $\left.\mu \mathrm{M}\right)$ (Chi et al., 2001a), and wogonin had the capacity to directly inhibit COX-2 at moderate concentrations (Chi et al., 2001b). Thus, it is clear that the majority of flavonoids do not exert an inhibitory action on COX-1 and COX-2 in general. Although several derivatives showed some inhibitory action, they were only weak inhibitors of COX-2 and COX-1. High concentrations (greater than $50-100 \mu \mathrm{M}$ ) were needed to obtain meaningful inhibition.

The effect on inducible NOS (iNOS) was also investigated since iNOS was also found to be closely associated with the inflammatory response. However, the results were also disappointing. Most flavonoids did not affect iNOS enzymatic activity (Kim et al., 1999a). The only exception was echinoisoflavanone $\left(\mathrm{IC}_{50}: 83 \mu \mathrm{M}\right)$, which inhibited iNOS activity in li- 
popolysaccharide (LPS)-induced RAW 264.7 cells (Cheon et al., 2000).

As described above, $\mathrm{ED}_{50}$ or $\mathrm{IC}_{50}$ concentrations needed to reasonably affect COX-1 or COX-2 enzymatic activity were found to be over $50-100 \mu \mathrm{M}$ in the case of the flavonoids showing some inhibitory action. The iNOS-inhibiting flavonoids also possessed $\mathrm{IC}_{50}$ values of over $50 \mu \mathrm{M}$. However, these flavonoid concentration ranges could not be easily attained in the body. The expected blood concentrations are 1-10 $\mu \mathrm{M}$ when flavonoids are orally administered at doses of $10-100 \mathrm{mg} / \mathrm{kg}$. If we assume $10-20 \%$ bioavailability and the maximum dose of $1 \mathrm{~g} /$ person is orally administered, 100-200 $\mathrm{mg}$ is absorbed. If the total blood volume is assumed to be 5 $\mathrm{L}$, the maximum concentrations of $100-200 \mathrm{mg} / 5,000 \mathrm{~mL}(20-$ $40 \mathrm{mg} / \mathrm{L}$ ) may be obtained. This is equivalent to approximately $100 \mu \mathrm{M}$ or less. However, these concentrations are maximum blood concentrations, which could be obtained for only a short time period. And there is another problem to consider. It is well known that flavonoids are rapidly transformed into several glycoside derivatives once they are absorbed into the body. Since flavonoid glycosides, in general, do not show activity comparable to flavonoid aglycones, this transformation further lowers the blood concentrations of the active derivatives. Thus it is reasonable to think that the maximum achievable concentration ranges of orally ingested flavonoids in blood are 10-20 $\mu \mathrm{M}$. These flavonoid concentration ranges were not enough to considerably inhibit the enzymatic activity of pro-inflammatory enzymes such as COX-1, COX-2, and iNOS as described above. All these findings and speculations concerning the effect on pro-inflammatory enzymes are contradictory to the previous belief that flavonoids might show anti-inflammatory activity mainly by inhibiting the activity of pro-inflammatory enzymes such as COX and NOS isoforms. Therefore, the major anti-inflammatory action mechanisms of flavonoids are not likely the inhibition of pro-inflammatory enzymes including COX and iNOS isoforms, and probably, others. These findings suggest that another major anti-inflammatory mechanism(s) of flavonoids must exist.

\section{CELLULAR ACTION MECHANISMS OF FLAVONOIDS}

When the effects on the inducible pro-inflammatory enzyme iNOS were investigated about 20 years ago, certain flavones and flavonols including apigenin, wogonin, and luteolin were found for the first time to down-regulate iNOS expression in LPS-treated RAW 264.7 cells at low concentrations ranges of 1-10 $\mu \mathrm{M}$, which are pharmacologically achievable concentrations (Kim et al., 1999a). Prenylated flavonoids including kuwanon $C$ and sanggenon $B$ and some biflavonoids such as ginkgetin and ochnaflavone also down-regulated iNOS induction at $10 \mu \mathrm{M}$ (Cheon et al., 2000). Some flavonoids also inhibited the expression of COX-2 at similar concentration ranges. Most importantly, wogonin showed a potent down-regulating effect on iNOS and COX-2 induction in LPS-induced RAW 264.7 cells at low concentration ranges (Chi et al., 2001a). Prenylated flavonoids including sophoraflavanone $G$ also down-regulated COX-2 induction in LPS-treated RAW 264.7 cells at low concentrations (Kim et al., 2002). To find the effect on other cell types, wogonin was added to tetradecanoylphorbol-13-acetate (TPA), interleukin (IL)-1 $\beta$, or tumor necrosis factor (TNF)- $\alpha$-pretreated NIH/3T3 skin fibroblast cells, and the same compound was found to inhibit COX-2 expression (Chi and Kim, 2005). All these studies revealed that certain flavonoids down-regulated the expression of pro-inflammatory molecules in vitro at low concentrations. To extend these results to an in vivo system, some selected flavonoids were topically smeared onto inflamed mouse ear tissue to achieve effective concentrations of flavonoids that may not be possible by oral ingestion, as described above. The ear tissue was excised and sliced and the tissue homogenates were analyzed. This study led to the novel findings that the topical application of wogonin to mice skin inhibited TPA-induced COX-2 induction at doses of $50-200 \mu \mathrm{g} / \mathrm{site} /$ treatment with the concomitant inhibition of other inflammatory responses (Park et al., 2001). However, the same compound did not affect the expression level of COX-1, a constitutive form of COX. One biflavonoid, ginkgetin, also showed similar effects on TPA-treated mouse skin (Kwak et al., 2002). It is important to show that wogonin also down-regulated the expression of several pro-inflammatory genes in mouse skin (Chi et al., 2003). The topical local application of wogonin inhibited COX-2 and IL-1 $\beta$ gene expression in mouse ear arachidonic acid-induced inflammation but did not affect COX-1 and fibronectin gene expression. The same compound also reduced the gene expression of proinflammatory molecules (COX-2, IL-1 $\beta$, ICAM-1, and TNF- $\alpha$ ) against multiple TPA-treated subchronic model of skin inflammation on mouse ear, without affecting COX-1 and fibronectin gene expression. These differential regulatory effects of wogonin were also confirmed in contact dermatitis models using phenol and picryl chloride as irritants (Lim et al., 2004; Kim, 2005). It was also found that topical treatment of ginkgetin on the chronic skin inflammation mouse model reduced inflammatory responses including the down-regulation of IL$1 \beta$ induction (Lim et al., 2006a). With these in vivo findings and the above in vitro studies, it is proposed that the major action mechanism of the anti-inflammatory flavonoids is the transcriptional down-regulation of inflammation-related genes (Kim et al., 2004, 2008). And this concept is now generally accepted worldwide.

\section{FINDING OPTIMAL CHEMICAL STRUCTURES OF FLAVONOIDS}

Next, it was important to discover the optimal flavonoid structures exerting the above effects. For this purpose, hundreds of compounds mainly based on the flavone structure were synthesized since previous findings showed that certain flavones such as apigenin and wogonin possessed strong down-regulating effects on iNOS and COX-2 induction in LPStreated RAW 264.7 cells and other cell systems, as well as mouse skin. Using these synthetic compounds, the down-regulating effects on iNOS and COX-2 were compared. Initially, compounds synthesized based on the Topliss rule were examined. Hydroxyl and/or methoxyl residues were introduced at the 5- and 7-positions of the flavone A-ring with B-ring substitutions of 4'- $\mathrm{H},-\mathrm{Cl}$, -Me, -OMe or 3',4'- $\mathrm{Cl}_{2}$ (Fig. 2). 5-Hydroxy7-methoxyflavone derivatives (S-I) were found to moderately inhibit COX-2-catalyzed prostaglandin $\mathrm{E}_{2}\left(\mathrm{PGE}_{2}\right)$ production in LPS-treated RAW 264.7 cells (Dao et al., 2003a). Vinyl or allyl groups were introduced to the ring to resemble prenylated flavonoids and they also showed moderate action (Dao et al., 2003b). In a subsequent study, chrysin derivatives (S-II) were 
<smiles>[R]Oc1ccc(-c2cc(=O)c3c(O)cc(OC)cc3o2)cc1</smiles><smiles>COc1cccc(O)c1C(=O)/C=C/c1cccc(Br)c1</smiles><smiles></smiles><smiles>COc1ccc(-c2cc(=O)c3ccc(OC)cc3o2)c(OC)c1</smiles><smiles>O=c1cc(-c2ccc(-c3ccc4oc(-c5ccccc5)cc(=O)c4c3)cc2)oc2ccccc12</smiles><smiles>O=c1cc(-c2ccccc2)oc2c(-c3ccncc3)c(O)cc(O)c12</smiles>

S-IV<smiles>COc1ccccc1C(=O)/C=C/c1ccc(Cl)c(Cl)c1</smiles><smiles>O=c1cc(-c2ccccc2)oc2ccc(-c3c(O)cc4oc(-c5ccccc5)cc(=O)c4c3O)cc12</smiles><smiles>[Y][SH][X]c1cc(=O)c2ccc(Oc3ccc4oc(-c5ccccc5)cc(=O)c4c3)cc2o1</smiles>

Fig. 2. Some interesting synthetic flavonoids mentioned in this study.

prepared and 7-hydroxy-3',4'dichloroflavone, 7-methoxy-3',4'dichloroflavone, and 5-methoxy-3',4'-dichloroflavone showed higher potency (4-fold) in COX-catalyzed $\mathrm{PGE}_{2}$ production compared to that of wogonin (Dao et al., 2004a). To prepare wogonin-mimics, several 8-substituted derivatives were also synthesized including 8-aryl derivatives (Dao et al., 2004b) and 6,8-disubstituted derivatives (Park et al., 2005). However, in general, they did not show action comparable to that of wogonin. Several wogonin derivatives with B-ring various substitutions did not strongly inhibit COX-2 (Jang et al., 2005). During these studies, one compound, 2',4',7-trimethoxyflavone (S-III), was found to strongly inhibit $\mathrm{PGE}_{2}$ production in LPS-treated RAW 264.7 cells, but this compound was proved to be a phospholipase $\mathrm{A}_{2}\left(\mathrm{PLA} \mathrm{A}_{2}\right)$ inhibitor, not a COX-2 inhibitor or a down-regulator (Han et al., 2005). Some wogonin derivatives with $\mathrm{C}-8$ halogen substitutions were also synthesized and showed moderate anti-inflammatory action (Gurung et al., 2009). One particular compound, 5,7-dihydroxy-8-(pyridine$4 \mathrm{yl}$ )flavone (S-IV), was found to possess the same classical action as other flavonoids like apigenin, and this compound strongly inhibited the expression of pro-inflammatory genes such as iNOS and COX-2 (Lim et al., 2011a). However, its potency was not significantly higher than that of its natural counterparts, apigenin and wogonin.

It is worth mentioning that certain chalcones showed results similar to those of the flavones. Several synthetic chalcone derivatives exerted strong inhibitory action on iNOS-catalyzed NO production mainly by down-regulating iNOS induction (Kim et al., 2007). The compounds were 2-methoxy-3',4'-dichlorochalcone (S-V) and 2'-hydroxy-3-bromo-6'-methoxychalcone (S-VI). Some structures were shown below. In addition, several synthetic biflavonoids exerted anti-inflammatory activity. 
One synthetic C-C biflavonoid, 6-6" biflavone (S-VII), inhibited COX-2-catalyzed $\mathrm{PGE}_{2}$ production $\left(\mathrm{IC}_{50}\right.$ of $\left.3.7 \mu \mathrm{M}\right)$ in LPStreated RAW 264.7 cells compared to an $\mathrm{IC}_{50}$ of $8.2-20.7 \mu \mathrm{M}$ of the natural biflavone, ginkgetin. However, the inhibition was found to be mediated by direct COX-2 inhibition not by downregulation (Park et al., 2006a). To extend this study, several derivatives of C-C 6-6" biflavone were synthesized. Among these, one compound (5,7-dihydroxy[6,6"]biflavone, G168, S-VIII) was found to exert strong anti-inflammatory activity and down-regulated iNOS, but not COX-2 (Lim et al., 2009). This compound may be used as a future synthetic lead for new anti-inflammatory drug development. Some other C6O-C7" biflavone derivatives (S-IV) were prepared and some of them showed potent $\mathrm{PGE}_{2}$ inhibitory action in LPS-treated RAW 264.7 cells (Che et al., 2009). Despite these extensive studies, we could not find superactive compounds. Even the wogonin derivatives did not show significantly higher activity. However, from all these previous studies, the optimum basic flavone structures were shown to be 5, 7, and/or 4'-substituted (hydroxyl) flavones with or without substitution at C-8 and/or C-3'. The natural flavonoids apigenin, chrysin, kaempferol, and quercetin belong to the group of optimum structures and showed significant anti-inflammatory action. Thus, these natural flavonoids may be used for future clinical studies.

\section{LOCAL TREATMENT WITH FLAVONOIDS}

According to the in vivo findings, the oral administration of flavonoids does not result in high pharmacological action. Thus, it is evident that local treatment with flavonoids is needed (for example, skin application) to avoid extensive metabolism by the conversion to inactive compounds or to avoid situations where large amounts of flavonoids need to be administered orally (Fig. 3). However, they could be useful for

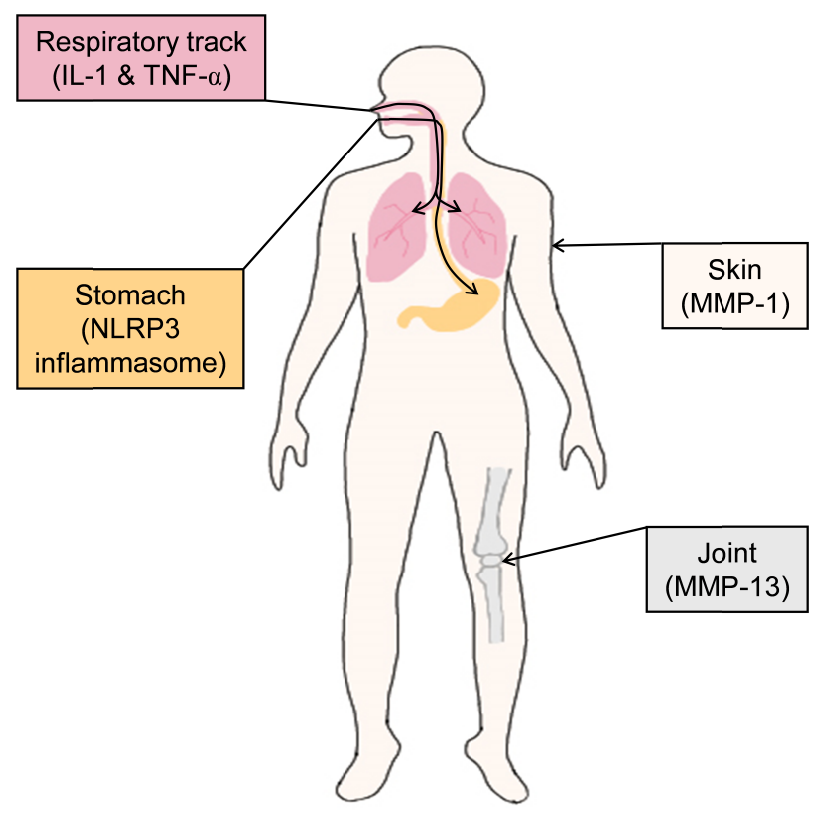

Fig. 3. Possible routes of local treatment of flavonoids and target molecules. some inflammatory disorders that could be controlled by low doses of flavonoids given orally (for example, less than $10 \mathrm{mg} /$ $\mathrm{kg}$ oral dose). The following studies are some recent trials in my laboratory to make target flavonoids useful agents.

First, applying flavonoids directly to the skin may be effective in treating skin inflammatory disorders. The effects of various flavonoids on skin inflammation in animal models were previously summarized (For review: Kim, 2007). Flavonoids were applied topically directly to skin lesions in the form of a cream or emulsion. Plant extracts containing flavonoids are used for cosmetic preparations, especially for skin inflammatory conditions. For instance, plant extracts such as mung bean extract containing flavonoids (vitexin and isovitexin) as the major constituents were successfully utilized as cosmetic ingredients (Kim et al., 1998a; Lim et al., 2006b). However, in another attempt, when flavonoid-enriched fractions from several plant extracts including Ginkgo biloba leaves were prepared and combined as a cosmetic formulation and used to treat inflamed human skin, some effects were seen, but the potency was not enough for clinical use (unpublished results). When the extracts or fractions are used, increased potency is a prerequisite for future use for inflammatory skin disorders. As single compounds, wogonin and ginkgetin were smeared on mouse skin and found to exert anti-inflammatory effects (Kwak et al., 2002; Chi et al., 2003; Lim et al., 2004).

As part of a mechanism study related to skin inflammation, the effect of flavonoids on matrix metalloproteinase-1 (MMP1) expression was examined since flavonoids are down-regulators of pro-inflammatory molecule expression. MMP-1 (collagenase) is associated with some chronic skin inflammatory disorders. Initially, the effect of various flavonoids on MMP-1 activity was examined. The enzymatic inhibitory action of flavones/flavonols against bacterial collagenase was elucidated. Most flavonoids did not affect collagenase activity, while some flavonols inhibited collagenase only at high concentrations. The $I_{50}$ value of quercetin was $286 \mu \mathrm{M}$ (Sin and Kim, 2005). Synthetic flavone derivatives did not show considerable activity either (Park et al., 2006b). In contrast, certain flavonoids inhibited MMP-1 induction in inflammagen-treated skin fibroblasts at reasonable concentration ranges. Flavonoids including quercetin, kaempferol, apigenin, and wogonin downregulated MMP-1 induction in TPA-treated human dermal fibroblasts (Lim and Kim, 2007). And MMP-1 down-regulation was shown for the first time to be mediated, at least in part, by the inhibition of activator protein-1 (AP-1) activation through blocking mitogen-activated protein kinase (MAP kinase) activation. Thus, some chronic skin inflammatory disorders like atopic dermatitis might be controlled by the topical application of certain flavonoids. In the future, this possibility should be examined clinically.

Secondly, flavonoids could be intra-articularly injected into the joint space as a local treatment for chronic cartilage inflammatory diseases like rheumatoid arthritis (RA) and osteoarthritis (OA). RA is a chronic inflammatory disease of the joint area provoked by an autoimmune attack. In the RA joint space, high concentrations of pro-inflammatory molecules such as IL-1 and TNF- $\alpha$ are present and play an essential role in provoking consistent chronic inflammation. Flavonoids are known to down-regulate the induction of these molecules. For example, the peritoneal injection of one biflavone, ginkgetin, was found to strongly inhibit adjuvant-induced arthritic inflammation in rat joints (Kim et al., 1999b). This animal mod- 
el represents human RA. If the dosing form for intra-articular injection is properly developed, more efficient treatment may be achieved. In contrast, OA is a disease of long-term deterioration of the cartilage mainly due to the aging process. Some MMPs are closely related to these chronic inflammatory disorders like joint inflammation. In OA cartilage and the joint space, various MMPs and aggrecanases are highly induced and they degrade cartilage material, which is comprised of collagenous materials and aggrecans. Of these enzymes, MMP13 is the pivotal one mainly degrading cartilage collagenous material. Thus, the down-regulation of MMP-13 may contribute to protecting against progressive OA. In this respect, the effects of flavonoids on MMP-13 induction were investigated. In cartilage chondrocytes (SW1353), treatment with IL-1 $\beta$ induced inflammatory responses including the expression of pro-inflammatory molecules like MMP-13. These cells activated the MAPK, activator protein-1 (AP-1), nuclear transcription factor- $\kappa B(N F-\kappa B)$, and Janus kinase (JAK)/signal transducers and activators of transcription (STAT) pathways (Lim and Kim, 2011). p38 MAPK inhibitor (SB203580) and JAK2 inhibitor (AG490) blocked MMP-13 expression. Several flavonoids inhibited MMP-13 induction at pharmacologically achievable concentrations. Especially, apigenin and wogonin strongly inhibited MMP-13 expression mainly via inhibiting the AP-1 and JAK/STAT pathways (Lim et al., 2011b). Moreover, it was also proved that apigenin protected cartilage degradation in a rabbit cartilage explant culture. These results suggest that certain flavonoids have the potential to protect cartilage destruction especially for clinical use in OA if properly introduced into the synovial joints using special formulations.

Third, acting on the stomach wall is another type of local treatment to avoid systemic transformation to inactive derivatives. Flavonoids may be orally administered and act directly on the gastrointestinal wall during absorption. Among the recently found inflammatory mechanisms, the inflammasome activation pathway is worth mentioning. Of several inflammasomes reported so far, the NOD-like receptor family, pyrin domain-containing 3 (NLRP3) inflammasome is well studied and many inflammatory disorders are related to the activation of this molecule. The agents that inhibit activation of the NLRP3 inflammasome may have potential as new anti-inflammatory drugs. One of several NLRP3 inflammasome-associated diseases is Helicobacter pylori-related gastric inflammation. $H$. pylori induces an inflammatory response in the gastric and intestinal mucosa. Importantly, $H$. pylori is known to activate the NLRP3 inflammasome, mainly by stimulation through their flagella. The activated NLRP3 inflammasome produces active IL-1 and IL-18. These pro-inflammatory cytokines assist in accelerating $H$. pylori infection as well as inflammation of the stomach wall. The long-term persistent infection leads to chronic gastritis and eventually gastric cancer. Thus, it is reasonable to think that blocking NLRP3 inflammasome activation may reduce $H$. pylori-induced gastritis. When various flavonoids were examined in $H$. pylori-treated human monocytic cell line (THP-1), some of them significantly reduced IL-1 and IL-18 production. The mechanism of action mediated by these flavonoids was shown to be by blocking NLRP3 inflammasome activation (Lim et al., 2018). Especially, apigenin, kaempferol, and 3',4'-dichloroflavone reduced IL-1 production by blocking apoptosis-associated speck-like protein containing a caspase recruitment domain (ASC) oligomerization without affecting intracellular ASC levels. Apigenin inhibits the activation of the NLRP3 inflammasome by interrupting the activation of the spleen tyrosine kinase/protein tyrosine kinase 2 (Syk/Pyk2) pathway. In a continuing study, THP-1 cells activated with $H$. pylori were treated with chalcone derivatives. In H. pylori-stimulated cells, chalcones such as 2'-hydroxy-4',6'dimethoxyflavone and 2'-hydroxy-3,4,5-trimethoxyflavone strongly inhibited NLRP3 inflammasome activation without affecting the expression levels of the inflammasome components, NLRP3, ASC, and procaspase-1 (Choi et al., 2021). The cellular action mechanisms of the chalcones include inhibiting the interferon-1 receptor-associated kinase 4 (IRAK4) and $I_{\kappa} B \alpha / N F-\kappa B$ signaling pathways. These results suggest that some chalcones may be beneficial in treating $H$. pyloriinduced gastric disease by oral administration. Therefore, the digestion of appropriate amounts of flavonoids and chalcones in a regular diet (vegetables and fruits) may help to reduce the harmful effects of $H$. pylori infection. This notion waits for clear proof in future in vivo studies. Moreover, some gastric floatingtype formulations containing flavonoids and/or chalcones may prolong contact time with the stomach wall and thus, probably produce more favorable results.

\section{LOW-DOSE SYSTEMIC TREATMENT WITH FLAVONOIDS}

Finally, it is significant to mention that the oral administration of low-dose flavonoids could act on the aging process. In recent years, research on new roles and new pathways of inflammation has been expanded. New concepts have emerged and new inflammatory pathways have been elucidated. Now, inflammation-related diseases cover chronic inflammatory conditions including metabolic inflammation, aging, and cancer formation. For example, aging is closely related to inflammatory responses, called inflammaging, and is related to latestage cancer.

When cells age, they stop proliferating (cellular senescence) accompanied by the characteristic features of aging. However, without senescence and apoptotic death, the accumulating defective cells and tissues may transform into cancerous cells, and ultimately, produce cancer. Thus, cellular senescence has a beneficial role in the healthy aging process. In this regard, direct senescence inhibitors may not be beneficial. If treatment with senescence blockers is performed to delay the aging process, more deleterious effects may accumulate, as described above. Importantly, aging cells synthesize and secrete various pro-inflammatory molecules, also called senescence-associated secretory phenotype (SASP) molecules, into their environment. SASP is comprised of inflammatory cytokines such as IL-1, IL-6, and IL-8, and MMPs. SASP induces an inflammatory response in nearby cells and tissues, leading to inflammation, aging, and possibly cancer. Therefore, the agents only inhibiting SASP production without affecting the senescence capacity are meaningful in promoting a healthy aging process. As the fourth approach in flavonoid therapy, based on the above concept, the effect of flavonoid treatment on the aging process was examined to determine whether flavonoids could act at low concentrations even by oral administration.

Certain flavonoids were found to block SASP production for the first time without affecting cellular senescence in vitro and in vivo (Lim et al., 2015). The cellular action mechanisms 
were found to inhibit NF-кB p65 activity via the interleukin-1 receptor-associated kinase 1 (IRAK1)// $\mathrm{KB} \alpha$ signaling pathway. And these flavonoids also inhibited $I_{\kappa} B \zeta$ activation. The inhibitory mechanisms were similar to those of flavonoids on the H. pylori-induced inflammasome pathway (Choi et al., 2021). The strongest inhibitors were apigenin and kaempferol. Further study with 17 flavonoid derivatives isolated from the radix of Scutellaria baicalensis confirmed the previous results. Some of them inhibited SASP production without abrogating cellular proliferation (Lim et al., 2020). The mechanism study also showed similar results. The active derivatives inhibited the activation of $I \kappa B \zeta$. And some flavones also interfered with the activation of the CCAAT/enhancer-binding protein $\beta$ (CEBP $\beta$ ) pathway. All these results indicate that certain flavonoids have the potential to treat the aging process, leading to healthy aging. An in vivo study using aged rats also showed a SASP inhibitory effect. Oral apigenin and 2',5,7-trihydroxyflavone treatment at doses as low as $2-4 \mathrm{mg} / \mathrm{kg} /$ day exerted significant SASP inhibitory effects and inhibited $\mathrm{I} \mathrm{B} \zeta$ activation in aged rat kidneys (Lim et al, 2015, 2020), which importantly suggests that flavonoids are effective in the aging process at low doses by oral administration. If these results could be extended to a human study, a daily low dose of oral flavonoid might be shown to be beneficial for the healthy aging process. These studies also suggest that flavonoids may be applicable to treating chronic inflammatory disorders by oral as well as local treatment, as long as they act at low doses systemically.

\section{FUTURE PERSPECTIVES}

There have been many clinical studies on the effect of single flavonoid compounds or flavonoid-containing foods on various disease conditions. Of these, one recent cohort study is very convincing (Bondonno et al., 2019). Massive numbers of humans $(>50,000)$ were observed for 23 years. There was a strong inverse relationship between daily flavonoid consumption and death incidence from cancer and cardiovascular-related diseases. Flavonoid ingestion could provide clear benefits to humans. Although human clinical studies of long-term flavonoid consumption and inflammatory disorders are rare, I am strongly convinced that high flavonoid consumption may produce great benefits in reducing the progression of chronic inflammatory disorders and the aging process. This will be unveiled by a new well-controlled clinical study. Researchers studying anti-inflammatory flavonoids worldwide are waiting for the results.

In the near future, the application of flavonoid-enriched preparations for the above inflammatory disorders will be more feasible than using a single flavonoid molecule. For example, flavonoid-enriched fractions from the roots of Sophora flavescence and the root barks of Broussonetia papyrifera showed strong anti-inflammatory effects in animal models of inflammation (Jin et al., 2010a, 2010b; Ko et al., 2013; Lim et al., 2013). For these purposes, the flavonoid-enrichment techniques and standardization method should be improved. Using these modern techniques, more reliable clinical results could be obtained, and eventually, flavonoids could be used as functional foods or drugs. Until then, eating a lot of vegetables and fruits with high flavonoid content and low sugar content is strongly recommended.

\section{BIBLIOGRAPHY AND ACKNOWLEDGMENTS}

The author graduated from the College of Pharmacy, Seoul National University (B.S.) (1979) and completed a Ph.D. degree at KAIST (1984). He has been an assistant professor (1986-1989), associate professor (1990-1994), and professor (1995-2022) at the College of Pharmacy, Kangwon National University, Korea. He is now a professor emeritus of the same institution. He was also the President of the Korean Society of Applied Pharmacology (2012). He has published more than 200 papers in international as well as domestic journals and contributed to achieving more than 30 patents during his academic career. Prof. Kim would like to thank all collaborators, and M.S. and Ph.D. students in his laboratory. Especially, Drs. Sam Sik Kang, Yeong Shik Kim (Seoul National University), Hyeun Wook Chang (Yeungnam University), and Kun Ho Son (Andong National University) are greatly acknowledged. The late Dr. Moon Young Heo (Kangwon National University) was a life-long collaborator and friend. Many research papers would not have been successfully published without the sincere dedication of Dr. Hyun Lim (Kangwon National University). Many thanks are given to the mentors, the late Dr. Si Myung Byun (KAIST), late Dr. Henry J. Lee (Florida AM University), and late Dr. Vincent A. Ziboh (UC Davis). Every faculty member of the College of Pharmacy (Kangwon National University) is acknowledged. Special thanks are given to Dr. Haeil Park (synthesis of flavonoid derivatives) and Dr. Yong Soo Kwon (isolation of flavonoids) at Kangwon National University. Dr. Jae Hoon Cheong (Chonbuk National University) and Dr. Jong Hoon Ryu (Kyunghee University), members of KSAP, are acknowledged. Finally, Prof. Kim would like to express sincere appreciation to Dr. In Koo Chun (Dongduk Women's University) for the mentoring and life-long friendship. My laboratory could not be maintained and managed without research grants from the governmental institutions and many industrial companies. In particular, the research grants from the National Research Foundation of Korea (NRF) (MSIT, NRF-2019R1F1A1051567), BK21-plus of the Ministry of Education (Korea), Angook Pharmaceutical Co., SK chemical Ltd., and Coreana Cosmetics are greatly acknowledged.

\section{REFERENCES}

Bondonno, N. P., Dalgaard, F., Kyrø, C., Murray, K., Bondonno, C. P., Lewis, J. R., Croft, K. D., Gislason, G., Scalbert, A., Cassidy, A., Tjønneland, A., Overvad, K. and Hodgson, J. M. (2019) Flavonoid intake is associated with lower mortality in the Danish Diet Cancer and Health Cohort. Nat. Commun. 10, 3651.

Che, H., Park, B. K., Lim, H., Kim, H. P., Chang, H. W., Jeong, J.H. and Park, H. (2009) Synthesis of biflavones having a 6-O-7" linkage and effects on cyclooxygenase- 2 and inducible nitric oxide synthase. Bioorg. Med. Chem. Lett. 19, 74-76.

Cheon, B. S., Kim, Y. H., Son, K. H., Chang, H. W., Kang, S. S. and Kim, H. P. (2000) Effects of prenylated flavonoids and biflavonoids on lipopolysaccharide-induced nitric oxide production from the mouse macrophage cell line RAW 264.7. Planta Med. 66, 596-600.

Chi, Y. S., Cheon, B. S. and Kim, H. P. (2001a) Effect of wogonin, a plant flavone from Scutellaria radix, on the suppression of cyclooxygenase-2 and the induction of inducible nitric oxide synthase in lipopolysaccharide-treated RAW 264.7 cells. Biochem. Pharmacol. 61, 1195-1203.

Chi, Y. S., Jong, H. G., Son, K. H., Chang, H. W., Kang, S. S. and Kim, H. P. (2001b) Effects of naturally occurring prenylated flavonoids on enzymes metabolizing arachidonic acid: cyclooxygenases and 
lipoxygenases. Biochem. Pharmacol. 62, 1185-1191.

Chi, Y. S. and Kim, H. P. (2005) Suppression of cyclooxygenase-2 expression of skin fibroblasts by wogonin, a plant flavone from Scutellaria radix. Prostaglandins Leukot. Essent. Fatty Acids 72, 59-66.

Chi, Y. S., Lim, H., Park, H. and Kim, H. P. (2003) Effects of wogonin, a plant flavone from Scutellaria radix, on skin inflammation: in vivo regulation of inflammation-associated gene expression. Biochem. Pharmacol. 66, 1271-1278.

Choi, H. R., Lim, H., Lee, J. H., Park, H. and Kim, H. P. (2021) Interruption of Helicobacter pylori-induced NLRP3 inflammasome activation by chalcone derivatives. Biomol. Ther. (Seoul) 29, 410-418.

Dao, T. T., Chi, Y. S., Kim, J., Kim, H. P., Kim, S. and Park, H. (2003a) Synthesis and $\mathrm{PGE}_{2}$ inhibitory activity of 5,7-dihydroxyflavones and their O-methylated flavone analogs. Arch. Pharm. Res. 26, 345350.

Dao, T. T., Chi, Y. S., Kim, J., Kim, H. P., Kim, S. and Park, H. (2004a) Synthesis and inhibitory activity against COX-2 catalyzed prostaglandin production of chrysin derivatives. Bioorg. Med. Chem. Lett. 14, 1165-1167

Dao, T. T., Kim, S. B., Sin, K.-S., Kim, S., Kim, H. P. and Park, H. (2004b) Synthesis and biological activities of 8-arylflavones. Arch Pharm. Res. 27, 278-282.

Dao, T. T., Oh, J. W., Chi, Y. S., Kim, H. P., Sin, K.-S. and Park, H. (2003b) Synthesis and $\mathrm{PGE}_{2}$ inhibitory activity of vinylated and allylated chrysin analogues. Arch. Pharm. Res. 26, 581-584.

Gurung, S. K., Kim, H. P. and Park, H. (2009) Inhibition of prostaglandin $\mathrm{E}_{2}$ production by synthetic wogonin analogs. Arch. Pharm. Res. 32, 1503-1508.

Han, C. K., Son, M. J., Chang, H. W., Chi, Y. S., Park, H. and Kim, H. P. (2005) Inhibition of prostaglandin production by a structurallyoptimized flavonoid derivative, 2',4',7-trimethoxyflavone and cellular action mechanism. Biol. Pharm. Bull. 28, 1366-1370.

Jang, J., Kim, H. P. and Park, H. (2005) Structure and antiinflammatory activity relationships of wogonin derivatives. Arch. Pharm. Res. 28, 877-884.

Jin, J. H., Lim, H., Kwon, S. Y., Son, K. H. and Kim, H. P. (2010a) Anti-inflammatory activity of the total flavonoid fraction from Broussonetia papyrifera in combination with Lonicera japonica. Biomol. Ther. (Seoul) 18, 197-204.

Jin, J. H., Kim, J. S., Kang, S. S., Son, K. H., Chang, H. W. and Kim, H. P. (2010b) Anti-inflammatory and anti-arthritic activity of total flavonoids of the roots of Sophora flavescens. J. Ethnopharmacol. 127, 589-595

Kim, B. J., Kim, J. H., Heo, M. Y. and Kim, H. P. (1998a) Anti-oxidative and anti-inflammatory activities of the mung bean. Cosmetics and Toiletries 113, 71-74.

Kim, D. W., Chi, Y. S., Son, K. H., Chang, H. W., Kim, J. S., Kang, S. S. and Kim, H. P. (2002) Effects of sophoraflavanone G, a prenylated flavonoid from Sophora flavescens, on cyclooxygenase-2 and in vivo inflammatory response. Arch. Pharm. Res. 25, 329-335.

Kim, H. K., Cheon, B. S., Kim, Y. H., Kim, S. Y. and Kim, H. P. (1999a) Effects of naturally occurring flavonoids on nitric oxide production in the macrophage cell line RAW 264.7 and their structure-activity relationships. Biochem. Pharmacol. 58, 759-765.

Kim, H. K., Namgoong, S. Y. and Kim, H. P. (1993) Antiinflammatory activity of flavonoids: mouse ear edema inhibition. Arch. Pharm. Res. 16, 18-24.

Kim, H. K., Son, K. H., Chang, H. W., Kang, S. S. and Kim, H. P. (1999b) Inhibition of rat adjuvant-induced arthritis by ginkgetin, a biflavone from Ginkgo biloba leaves. Planta Med. 65, 465-467.

Kim, H. P. (2005) Histopathological comparison of animal models of skin inflammation and inhibition of the inflammatory responses by plant flavonoid, wogonin. J. Appl. Pharmacol. 13, 133-137.

Kim, H. P. (2007) Molecular events on experimental skin inflammation and modulation by topical anti-inflammatory flavonoids. J. Appl. Pharmacol. 15, 7-15.

Kim, H. P., Mani, I., Iversen, L. and Ziboh, V. A. (1998b) Effects of naturally-occurring flavonoids and biflavonoids on epidermal cyclooxygenase and lipoxygenase from guinea-pigs. Prostaglandins Leukot. Essent. Fatty Acids 58, 17-24.

Kim, H. P., Park, H., Son, K. H., Chang, H. W. and Kang, S. S. (2008) Biochemical pharmacology of biflavonoids: implications for anti- inflammatory action. Arch. Pharm. Res. 31, 265-273.

Kim, H. P., Son, K. H., Chang, H. W. and Kang, S. S. (1996) Flavonoids: potential antiinflammatory agents. Nat. Prod. Sci. 2, 1-8.

Kim, H. P., Son, K. H., Chang, H. W. and Kang, S. S. (2000) Effects of naturally occurring flavonoids on inflammatory responses and their action mechanisms. Nat. Prod. Sci. 6, 170-178.

Kim, H. P., Son, K. H., Chang, H. W. and Kang, S. S. (2004) Antiinflammatory plant flavonoids and cellular action mechanisms. J. Pharmacol. Sci. 96, 229-245.

Kim, Y. H., Kim, J., Park, H. and Kim, H. P. (2007) Anti-inflammatory activity of the synthetic chalcone derivatives: inhibition of inducible nitric oxide synthase-catalyzed nitric oxide production from lipopolysaccharide-treated RAW 264.7 cells. Biol. Pharm. Bull. 30, 1450-1455.

Ko, H. J., Kwon, O. S., Jin, J. H., Son, K. H. and Kim, H. P. (2013) Inhibition of experimental systemic inflammation (septic inflammation) and chronic bronchitis by new phytoformula BL containing Broussonetia papyrifera and Lonicera japonica. Biomol. Ther. (Seoul) 21, 66-71.

Kwak, W. J., Han, C. K., Son, K. H., Chang, H. W., Kang, S. S., Park, B. K. and Kim, H. P. (2002) Effects of ginkgetin from Ginkgo biloba leaves on cyclooxygenases and in vivo skin inflammation. Planta Med. 68, 316-321

Lee, S. J., Baek, H. J., Lee, C. H. and Kim, H. P. (1994) Antiinflammatory activity of isoflavonoids from Pueraria radix and biochanin $A$ derivatives. Arch. Pharm. Res. 17, 31-35.

Lee, S. J., Son, K. H., Chang, H. W., Do, J. C., Jung, K. Y., Kang, S. S. and Kim, H. P. (1993) Antiinflammatory activity of naturally occurring flavone and flavonol glycosides. Arch. Pharm. Res. 16, 25-28.

Lim, H., Jin, J. H., Park, H. and Kim, H. P. (2011a) New synthetic anti-inflammatory chrysin analog, 5,7-dihydroxy-8-(pyridine-4yl) flavone. Eur. J. Pharmacol. 670, 617-622.

Lim, H. and Kim, H. P. (2007) Inhibition of mammalian collagenase, matrix metalloproteinase-1, by naturally-occurring flavonoids. Planta Med. 73, 1267-1274.

Lim, H. and Kim, H. P. (2011) Matrix metalloproteinase-13 expression in IL-1 $\beta$-treated chondrocytes by activation of the p38 MAPK/c-Fos/ AP-1 and JAK/STAT pathways. Arch. Pharm. Res. 34, 109-117.

Lim, H., Kim, S. B., Park, H., Chang, H. W. and Kim, H. P. (2009) New anti-inflammatory synthetic biflavonoid with C-C (6-6") linkage: differential effects on cyclooxygenase- 2 and inducible nitric oxide synthase. Arch. Pharm. Res. 32, 1525-1531.

Lim, H., Kwon, Y. S., Kim, D., Lee, J. and Kim, H. P. (2020) Flavonoids from Scutellaria baicalensis inhibit senescence-associated secretory phenotype production by interrupting $1 \kappa \mathrm{B} / / \mathrm{C} / \mathrm{EBP} \beta$ pathway: Inhibition of age-related inflammation. Phytomedicine 76, 153255.

Lim, H., Min, D. S., Park, H. and Kim, H. P. (2018) Flavonoids interfere with NLRP3 inflammasome activation. Toxicol. Appl. Pharmacol. 355, 93-102.

Lim, H., Park, H. and Kim, H. P. (2004) Inhibition of contact dermatitis in animal models and suppression of proinflammatory gene expression by topically applied flavonoid, wogonin. Arch. Pharm. Res. 27, 442-448.

Lim, H., Park, H. and Kim, H. P. (2011b) Effects of flavonoids on matrix metalloproteinase-13 expression of interleukin-1 $\beta$-treated articular chondrocytes and their cellular mechanisms: Inhibition of c-Fos/ AP-1 and JAK/STAT signaling pathways. J. Pharmacol. Sci. 116, 221-231.

Lim, H., Park, H. and Kim, H. P. (2015) Effects of flavonoids on senescence-associated secretory phenotype formation from bleomycininduced senescence in BJ fibroblasts. Biochem. Pharmacol. 96, 337-348.

Lim, H., Son, K. H., Chang, H. W., Kang, S. S. and Kim, H. P. (2006a) Effects of anti-inflammatory biflavonoid, ginkgetin, on chronic skin inflammation. Biol. Pharm. Bull. 29, 1046-1049.

Lim, H., Son, K. H., Chang, H. W., Kang, S. S. and Kim, H. P. (2006b) Inhibition of chronic skin inflammation by topical anti-inflammatory flavonoid preparation, Ato Formula ${ }^{\circledR}$. Arch. Pharm. Res. 29, 503507.

Lim, H. J., Jin, H. G., Woo, E. R., Lee, S. K. and Kim, H. P. (2013) The root barks of Morus alba and the flavonoid constituents inhibit airway inflammation. J. Ethnopharmacol. 149, 169-175. 
Kim. Review of Flavonoids: Anti-Inflammatory Action and Mechanism

Park, B. K., Heo, M. Y., Park. H. and Kim, H. P. (2001) Inhibition of TPA-induced cyclooxygenase-2 expression and skin inflammation in mice by wogonin, a plant flavone from Scutellaria radix. Eur. J. Pharmacol. 425, 153-157.

Park, H., Dao, T. T. and Kim, H. P. (2005) Synthesis and inhibition of $\mathrm{PGE}_{2}$ production of 6,8-disubstituted chrysin derivatives. Eur. J. Med. Chem. 40, 943-948.

Park, H., Kim, Y. H., Chang, H. W. and Kim, H. P. (2006a) Anti-inflammatory activity of the synthetic $\mathrm{C}-\mathrm{C}$ biflavonoids. J. Pharm. Pharmacol. 58, 1661-1667.
Park, H., Sin, B. Y. and Kim, H. P. (2006b) Inhibition of collagenase by anti-inflammatory synthetic flavones. J. Appl. Pharmacol. 14, 36-39.

Sin, B. Y. and Kim, H. P. (2005) Inhibition of collagenase by naturallyoccurring flavonoids. Arch. Pharm. Res. 28, 1152-1155.

You, K. M., Jong, H.-G. and Kim, H. P. (1999) Inhibition of cyclooxygenase/lipoxygenase from human platelets by polyhydroxylated/ methoxylated flavonoids isolated from medicinal plants. Arch. Pharm. Res. 22, 18-24. 